\title{
STUDY ON VORTEX FORMATION IN THE POURING BASIN BY DIRECT OBSERVATION
}

\author{
J. Runyoro \\ Department of Engineering Materials, University of Dar es Salaam \\ P.O. Box 35131, Dar es Salaam Tanzania
}

\begin{abstract}
A lthough the formation of vortex on the free surface of liquid draining from a container is often observed, relatively little is known about the phenomenon. When a liquid is drained from a container such as a bathtub through a bottom orifice, a dip on the surface known as vortex is formed. The vortex first appears as a small dimple in the free surface, which suddenly forms a cone-shaped hole. The vortex causes turbulences, which draws in air down into the orifice (drain).

Generally, the issue of vortex formation is so common in our lives that possibly its occurrence seems to be taken for granted and this is, perhaps why the subject has received relatively little scientific attention. Mathematically a derivation is known but it does not take into consideration variables such as shape and size of the container or the draining orifice. Experiments were carried out using containers of different shapes and sizes, orifices of different shapes and sizes placed at different points in the container. The minimum head in the container that prevents the formation of vortex has been determined and is the function of container and orifice geometry.
\end{abstract}

\section{Keywords}

Free vortex, pouring basin, orifices, film forming alloys, critical height, free surface

\section{INTRODUCTION}

Scientific principles are increasingly being applied to gating system, more attention being rendered to the sprue, runner and ingate components. Investigations on these elements have been carried out and detailed reviews of their designs and their effects on the quality of castings highlighted. However, pouring basin where the pouring and consequent filling of the casting commences, has received less consideration. It is important to note that the relative position of the pouring basin within the gating system renders it a big role to play in achieving the casting's quality.

Vortex formation on the surface of liquid during pouring process is a common phenomenon although little is known about it. In foundry practice it may lead to contamination of the molten metal by air/gases, slag and dross. A good knowledge of the behavior of the flow of liquids is necessary in order to be able to study vortex formation in a pouring basin.

A pouring basin, which can be described as the enlarged offset portion of the mouth of the gating system into which the molten metal is poured to flow, reach and fill the mold cavity acts as a reservoir for the molten metal during pouring process. When molten metal is poured in the pouring basin, atoms in liquid metal at the surface are attracted by the interior atoms and experience no balancing attraction from above the surface. This effect of atom cohesion causes the liquid metal surface to behave as though it were covered with an elastic membrane.

However, molten metal draining through the sprue entrance hole from a pouring basin, tends to form a whirlpool action in the spiral motion known as vortex, which occurs as the fluid level in the pouring basin decreases. This implies that the selection of the pouring basin should not only be governed by the requirement to rapidly and progressively introduce the metal to the sprue cavity but should also be dependent on among the other economic and practical considerations, the elimination of vortex formation in the metal. The optimum-pouring basin is one, which will eliminate vortex formation, deliver the metal to the sprue cavity within the shortest possible time and with least amount of metal poured in it. 
Previous work of Dergarabedian [1], Miles [2], Saad et al [3] and Bhuta et al [4] has indicated that the shape of the free surface is strongly affected by the drain and that draining introduces oscillations in an initially stationary free surface, and that the initial free-surface oscillations are damped by the drainage of the liquid. Past investigation of Lubin et al [5] were limited on studying parameters influencing the formation of the dip on the free surface of an initially stationary liquid draining from a cylindrical tank through a circular orifice. They missed out in their data such vital parameters as the various shapes and sizes of tank, various shapes of orifices, etc. Hence the work so far done does not describe explicitly the conditions at which vortex forms that is, at which a dip on a liquid surface reaches the level of the tank/container and the drain (Fig. 1).

Experiments were performed to study a range of parameters that influence vortex formation in liquid draining from a pouring basin through an orifice. The variables in these experiments will include among others: size and shape of the pouring basin, size and shape of orifice together with its location within the pouring basin, density of liquid, pressure at which the draining is taking place, etc. Based upon the experimental information obtained, an analysis will be presented indicating the criteria necessary to prevent vortex formation in a pouring basin. This approach will eliminate dependence on trial and error skills in designing pouring basins with a view of avoiding vortex formation, a task which has shown in practice to be costly in terms of casting quality and metal loss.

\section{LITERATURE REVIEW}

The literature review on a gating system is very wide, the present review will concentrate on scientific studies which have direct bearing on this work and includes observations of vortex formation in pouring basins and deductions which have been made that are relevant to the production of quality castings especially aluminum castings.

Titov et al [6] reported that at low level of molten metal in the pouring basins, air and slag on the surface of the metal could fall into the sprue and latter into the casting. Observation have revealed that molten metal poured into a pouring basin, during pouring process, tends to form a whirlpool action in a spiral motion known as vortex and this occurs as the liquid level over a basin decreases. However, Daughterly [7] showed that generally, exist two basic types of vortices namely: the forced vortex that is, rotation of fluid moving as solid about an axis and free vortex, that is, rotation of fluid by virtue of some rotation previously imparted to it or because of some internal action. It is this free vortex, which is the concern of this study.

Gulliver et al [8] highlighted the difficulty about vortex formation. It was revealed that vortex formation is a transition phenomenon from purely radial flow to a swirling flow and that the point of transition is not well defined because there is range of flow conditions over which either purely radial or swirling flow can occur, similar to the known transition from laminar to turbulent flow. The degree of turbulence of bulk liquid metal is proportional to the Reynolds's number. When Reynolds's number is less than 2000, the flow is laminar. However, the laminar flow starts to change into turbulent flow at a value of 2000 to 5000 depending on condition Campbell [9]. The change from laminar flow to turbulent flow may be caused by change in the flow pattern like fluid passing over a corner.

Runyoro [10] in his study on the design of gating system stated that the minimum head required to prevent vortex formation depended on flow characteristics in the pouring basin and that it was a function of flow rate. He however, carried out no specific work on the pouring basin to justify this case though he even proposed to reduce the metal velocity and increase metal depth in the pouring basin as measures to reduce vortex formation.

Lubin et al [5] showed that, the critical height at which a dip forms on the surface of a draining liquid whose top is subjected to another liquid, is independent of the initial height of the liquid in the tank for any given liquid-liquid combination. Their work further revealed the dependence of the critical height 
on the orifice area though they didn't consider changes in pouring basin shapes and sizes.

Campbell [11] highlighted the problem for film-forming alloys, which have their surfaces, covered with a solid oxide film that when the surface breaks, the surface film is folded over incorporated into the bulk of liquid. It acts as a crack and constitutes a nucleus for porosity and hot tears. One of the reasons that cause the liquid surface to break is vortex formation. So it is even more essential to prevent it in these film-forming alloys. Runyoro et al [12] in the work "Critical Gate Velocities for FilmForming Casting Alloys: A basis for Process Specification", show that almost all casting alloys form surface films and are therefore in danger of this problem, thus the increased desire to study vortex formation. They studied the way in which liquid aluminum alloy emerged from the gate into the mould, which have been effectively removed so that the emerging metal stream could be seen and studied in detail. The velocity of the metal emerging at the top of the gate was deduced by backward extrapolation of the height to time measurements. The experiments showed all $5 \mathrm{~mm}$ thick castings in which metal entered at a speed above $0.5 \mathrm{~m} / \mathrm{s}$ contained severe defects. For $10 \mathrm{~mm}$ thick castings, the critical velocity was observed to the nearer $0.3 \mathrm{~m} / \mathrm{s}$. They concluded that the critical velocity at which surface turbulence occurs is important. However, they admitted that castings are only good if the aspects of good practice are also taken into account including avoiding vortex formation in metal when pouring in the pouring basin.

Water coning in an oil reservoir, which is the raising of water layer towards the oil well is caused by the increased oil pumping rate and in their study, Lucas et al [13] found out that there is a critical pumping rate above which the water enters the oil well. This is similar to the filling up of the pouring basin with metal to avoid vortex formation. No efforts were made to determine the critical pumping rate.

Runyoro et al [14] in the study on the running and gating of light alloys used the pouring basins with overflows to avoid vortex effects. This confirms the importance of keeping the metal level in the pouring basin above the critical height. However, there isn't yet any established correlation between theoretical height and the other parameters that affects vortex formation.

Yonomoto et al [15] in a theoretical experimental study for liquid and gas entrainment to a small hole from stratified twophase region presented results of several hydraulic parameters, vortex flow among them, on the entrainment behavior. For the bottom break, results revealed the occurrence of vortex flow and liquid cross flow significantly affected entrainment as was observed by Smoglie and Reinmann [16]. It was shown that the conditions for the occurrence of vortex flow could be correlated with the Froude number $V_{2} \sqrt{ }\left(\mathrm{gh}_{2}\right)$ and the normalized water level $h / h_{b}$, where the subscript 2 indicates the outlet inside the main line, and a negative value of ' $\mathrm{V}_{2}$ ' means the flow direction is toward the break. It is indicated that vortex flow occurs when the following condition are satisfied: $\mathrm{V}_{2} / \mathrm{gh}_{2}<0.25$ and $\mathrm{h} / \mathrm{h}_{\mathrm{b}}>1.2$, Where, ' $h$ ' is the bulk water relative to the break, $h_{2}$ is the height of the water outlet, ' $\mathrm{H}_{\mathrm{b}}$ ' is the onset water level for entrainment ' $\mathrm{g}$ ' is the acceleration due to gravity. Vortex flow was suppressed by decreasing the value of $h / h_{b}$. This is in agreement with the general observation that vortex formation in a draining liquid can be suppressed by increasing the liquid level in the pouring basin.

\section{EXPERIMENTAL PROCEDURE}

In this research, a correlation between critical height and parameters of pouring basin, orifice, draining liquid and the pressure at which liquid is draining were investigated. Experiments were carried out on liquid flowing through an orifice in the bottom of a container and the critical depth at which an air core was formed was recorded (Fig. 2).

Several models of basins of different dimensions, shapes and sizes were used in these experiments (Fig. 3). In each case, water was drained or drawn through an orifice at the bottom of the container. The basin was constructed out of either pieces of plywood, glass or transparent perspex. Cylindrical 
models were made out of transparent thermoplastic material. The experiment involved direct observation of vortex formation through a transparent wall of a container and a graduated scale placed on the transparent side of the wall helped in measuring the critical depth at which vortex is formed.

The container was filled with water to the height of $80 \mathrm{~mm}$ before opening the bottom of the orifice. When the orifice was opened, water drained from the container and the critical depth was recorded when vortex started forming. During the experiment, various setting were used including;

a) Keeping the container size and shape constant, changing the size of the orifice.

b) Keeping the size of orifice constant, changing the size and shape of the container.

c) Keeping the size and shape of container and orifice constant, changing the orifice position.

d) Keeping the size of container and orifice constant, changing the shape of an orifice.

e) Keeping the size of container and orifice content, changing the orifice thickness.

f) Keeping the size of orifice constant, changing the size and shape of the container, applying pressure, and using different liquid medium.

\section{RESULTS}

The test results are shown from Fig. 4 to 10. Fig. 4 shows the straight-line variation of pouring basin cross sectional area to the critical height for rectangular $(1: 2,1: 1)$ and circular sections. Fig. 5 shows the variations between the critical heights with change in cross sectional area of circular orifice. The basins had approximately a cross sectional area of $100 \mathrm{~cm}^{2}$ and they had shapes of rectangular (1:1,1:2,1:4) and circular. The curves are parabolic shape.

The variation of orifice shapes using rectangular $(1: 1,1: 2,1: 4)$ and circular shapes on critical height using a cylindrical pouring basin and rectangular shape (1:2) are shown in Fig. 6. Investigations were made to check the effect of pouring basin size and shape on critical height using various sizes of circular orifices and the results are shown in Fig. 7. When using conical shaped basin, the critical height was plotted against the inlet/outlet diameter ratio of the container as shown in Fig. 8. The test was carried out to check the effect of offsetting the orifice from the center using rectangular, trapezoidal and circular basins and the results are shown in Fig. 9 for various settings. Cylindrical and rectangular containers were closed and pressurized before opening the orifice and measuring the critical height at which vortex forms under pressure using water, kerosene and petrol. The results are shown in Fig. 10.

\section{DISCUSSIONS}

Vortex formation due to a liquid draining out of the container is a very well known phenomenon but little attempt had been made to find the critical height with variation with sizes and shapes of the containers experimentally. Formulas have been attempted based on variation in pressure, density and flow rate of the liquid. The knowledge on vortex formation is important especially when pouring molten metal in castings especially light alloy metals which are prone to oxide formation and for applications where there is liquid/poisonous gas interfaces. There is a need to know the minimum height of liquid in the closed system in the case of leakage through a hole caused by corrosion of the container.

Vortex in containers can either be free or forced. Forced vortex is the one when the fluid in the container rotates with the container at the same angular velocity. No shear stress exists in the fluid and the only acceleration, which occurs, is directed inward towards the axis of rotation. All particles on the free surface will be in equilibrium under the action of their weight.

Free vortex is formed when the liquid rotates by virtue of some rotation previously imparted to it or because of some internal acceleration. No external energy is imparted to the liquid. Fluid poured over a drain, tends to form a whirlpool action in a spiral motion known as vortex. This occurs as the liquid level over a drain decreases. The vortex causes partial 
vacuum that draws in air down into the drain. Air drawn in the drain occupies part of the cross section thus tending to keep constant the flow rate of the liquid. The tests carried out were based on stationary liquid before allowing it to drain through the orifice.

For fluids in motion, the total potential, pressure energy and kinetic energy per unit weight of fluid is constant throughout a system. The kinetic energy is possessed by a mass of the fluid by virtue of its velocity while the potential energy is by virtue of its position and there may be positive or negative pressure. The energy formula based on the law of conservation of energy and known as Bernoulli's equation gives Potential head + velocity head + Pressure head + Friction loss $=$ Constant. At the beginning of the flow, the potential energy may be considered maximum. As the flow is established, the potential energy changes to kinetic and pressure energies respectively. As the liquid is being drained, it tends to keep the energy balance constant, but as the liquid decreases in the container, there is no enough liquid to keep the same flow rate and vortex is formed. The middle part of the vortex is filled by gas or air to compensate for liquid loss and tends to keep the liquid energy constant.

The experiment carried out has indicated that the size and shape of the pouring basin and orifice have significant effect on the critical height before the vortex is formed. As the pouring basin dimensions increases, the critical height also increases for the same size of the orifice as shown in Fig. 4. The square type has lowest values of critical height when compared with a circular shape. The pouring basin cross sectional area investigated was up to $200 \mathrm{~mm}^{2}$ for this experiment. The graph in fig. 4 indicates that for rectangular pouring basins with cross sectional areas less than $50 \mathrm{~mm}^{2}$, no vortex can be formed. For cylindrical shapes, the value is less than $20 \mathrm{~mm}^{2}$ for round orifice of $78.5 \mathrm{~mm}^{2}$ placed at the center of the basin.

An attempt was made to find the effect of varying the orifice diameter and using various shapes of the pouring basins as shown in Fig. 5. The orifice cross sectional area was varied from 100 to $500 \mathrm{~mm}^{2}$ and kept the pouring basin cross sectional area to $100 \mathrm{~cm}^{2}$. The circular basin has the highest tendency of forming vortex followed by rectangular shapes $(1: 1,1: 2$, $1: 4)$. Narrower rectangular pouring basin can be made with shallow height. In the casting of the metals, the minimum empirical height of the pouring basin is usually taken to be $25 \mathrm{~mm}$ [10]. The graph profiles obtained when using the cylindrical pouring basin of same cross sectional area in Fig. $5 \mathrm{~b}$ are identical to those in Fig. 5a except that critical height values are higher.

An experiment was carried out using a $200 \mathrm{~cm}^{2}$ rectangular pouring basin (1:2) and using various shapes and sizes of orifice openings. The highest value of critical height was obtained when using rectangular shapes (1:1, 1:2, 1:4) followed by circular shape. That may explain why in foundries, they prefer to use circular instead of rectangular sprues. According to Newtons first law of motion, the body in motion moves in a straight line at the same speed unless external force is exerted on it to change its motion. Any sudden or sharp change in the direction or speed of flow creates contraction and disturbances. This sort of contraction occurs in a flow from a large opening to a small one and vice versa or at any constriction in the flow system. The contraction is due to the momentum effect, which causes the stream to attempt to flow in a straight line even when it encounters an obstacle. The disturbances caused by liquid flowing out of the basin in the square orifice are higher than those in circular orifice and the liquid mass at the top is forced to whirlpool.

Variation of pouring basin sizes and shapes is shown in Fig. 7. As the cross sectional area of the cylindrical basin increases, the critical height increases with various sizes of orifice openings. The behavior is vise versa when using rectangular pouring basins. The explanation on this behavior may be due to the fact that in rectangular sections, there is enough amount of liquid which, when the orifice is opened, can keep the flow rate constant for a longer period that when compared to circular sections.

Experiment using conical cylinders was carried out with taper angle of up to 14 degrees. The 
graph showing critical height to inlet/outlet diameter ratios is shown in Fig. 8 for orifice openings of 10, 20 and $25 \mathrm{~mm}$ respectively. As the inlet to outlet diameter ratio increases, the critical height also increases. The smaller the orifice diameter, the lower the critical height at which the dip forms.

Most of the pouring basins do not have the sprue opening in the center but offset from the pouring point. In order to determine the effect of orifice offset on formation of vortex, three experiments were set up using rectangular (1:2), circular and trapezoidal basins and using 10, 15, 20 and $25 \mathrm{~mm}$ diameter orifice openings (Fig. 9). The findings are that when the offset increases, the critical height of vortex formation decreases. The critical height at which the dip formation commences is the function of the orifice size. In the case of the trapezoidal shaped basin, the critical height observed when water was passing through the orifice placed on the right side was higher than that observed when water passed through the left orifice. The farther the orifice location is from the center, the lower is the critical point. The critical height increases with a parabolic shape as the orifice cross sectional area increases.

Various liquid mediums were tested under pressure using circular and rectangular basins with a $6 \mathrm{~mm}$ diameter orifice (Fig. 10). The results show that the lower the pressure on the liquid, the higher is the critical height. Also, the higher is the density of the liquid, the higher is the critical height. Viscosity, as the measure of the capacity of the liquid to transmit a dynamic stress in shear was not considered in this experiment. In this experiment, the rectangular shape with bigger cross sectional area, the vortex was formed at very low height as when compared with a cylindrical shape with lower cross section area.

The obtained information is of vital importance in the foundry industry and the next stage on the work is to formulate a mathematical formula which can take in consideration most of the variables mentioned to forecast vortex formation onset in containers.

\section{MATHEMATICAL MODELLING OF VORTEX FORMATION}

The flow of fluid in any container is governed by science of fluids in motion. Based on these scientific principles and using factors derived from the measurements of variations from the ideal flow conditions, the formula for determining the vortex formation in basins can be derived to.

The basic law of motion based on the law of conversation of energy is known as Bernoulli's equation. It states that the total potential, pressure, and kinetic energy per unit weight of fluid is constant throughout a system. For any two points in the path of flow:

$$
\mathrm{H}_{1}+\mathrm{V}_{1}{ }^{2} / 2 \mathrm{~g}+\mathrm{P}_{1} / \rho=\mathrm{H}_{2}+\mathrm{V}_{2^{2}} / 2 \mathrm{~g}+\mathrm{P}_{2} / \rho+\mathrm{H}_{\mathrm{f}}
$$

Where $\mathrm{H}=$ Potential head measured above an arbitrary datum level, $\mathrm{V}=$ Linear velocity of flow, $\mathrm{P}=$ Pressure, $\mathrm{g}=$ Gravitational force, $\rho=$ fluid density and $\mathrm{H}_{\mathrm{f}}=$ frictional losses. For real fluids, the Bernoulli's equation may be rewritten as

$\mathrm{dH} / \mathrm{dr}=(\mathrm{V} / \mathrm{g})(\mathrm{dV} / \mathrm{dr}+\mathrm{V} / \mathrm{r})$

From this equation, three cases exist:

Case 1: A flow wherein $r=\infty$ and $d V / d r=0$. This is the flow where $\mathrm{H}=$ constant)

Case 2: A flow wherein $V \propto 1 / r$. Flow streamlines are circles of radius up to infinite.

Case 3: A flow wherein $V \propto r$. The fluid has the same angular velocity.

Case 2 closely approximate to free vortices including those occurring when a swirl occurs at an outlet to a container although the speed is far from infinite as in the center there is no free vortex formed. Assuming the free vortex motion extends from radius $r_{1}$ to radius $r_{2}$ where $\mathrm{r}_{2}<\mathrm{r}_{1}$ for case 2 , then $\mathrm{H}_{1}=\mathrm{H}_{2}$

Or $\mathrm{V}_{1^{2}} / 2 \mathrm{~g}+\mathrm{P}_{1} / \rho \mathrm{g}=\mathrm{V}_{2^{2}} / 2 \mathrm{~g}+\mathrm{P}_{2} / \rho \mathrm{g} \quad$ (eq. 3)

Considering $\mathrm{V}_{1}=\mathrm{C} / \mathrm{r}_{1}$ and $\mathrm{V}_{2}=\mathrm{C} / \mathrm{r}_{2}$ then,

$$
\left.\left(\mathrm{P}_{1}-\mathrm{P}_{2}\right) / \rho g=\mathrm{C}^{2}\left(1 / \mathrm{r}_{2}{ }^{2}-1 / \mathrm{r}_{1}{ }^{2}\right) / 2 \mathrm{~g} \quad \text { (eq. } 4\right)
$$


Since the velocity distribution is known $V=C / r$, the discharge $Q$ can be computed in terms of pressure rise as:

$\mathrm{Q}=\left(\mathrm{P}_{1}-\mathrm{P}_{2}\right) / \rho g$

The flow of fluid is also controlled by the law of continuity, and applies to both steady and unsteady flows in impermeable walled channels filled with incompressible fluid. It states that:

$\mathrm{Q}=\mathrm{A}_{1} \mathrm{~V}_{1}=\mathrm{A}_{2} \mathrm{~V}_{2}$

Where $\mathrm{Q}=$ Volumetric flow rates, $\mathrm{A}=$ cross sectional area and $\mathrm{V}=$ Velocity.

In the case of the jet issuing from an orifice, Torricelli's equation is used and states:

$\mathrm{V}=(2 \mathrm{gH})^{1 / 2}$

As the fluid is falling through a height, the cross sectional area of the stream decreases to conform to the law of continuity. This behavior accounts for the tapered shape of a free falling stream. Dimensions of a free falling stream at any point are given by a parabolic formula:

$\mathrm{A}_{1} / \mathrm{A}_{2}=\left(\mathrm{H}_{1} / \mathrm{H}_{2}\right)^{1 / 2}$

The formula proposed by Lubin etc [5] in calculating the formation of a dip on the surface of a liquid draining from a tank which applies to this study assumes the following:

a) the effects of viscosity of liquid are negligible

b) the effect of surface tension are negligible

c) at the instant prior to the formation of the dip the flow is steady

d) The initial depression (dip) on the surface develops so rapidly as to reach into the drain instantaneously.

By combining equations 6 and 7, the formula becomes $(2 \mathrm{gH}){ }^{0.5}=\mathrm{Q} / \mathrm{A}_{2}$

Therefore $\mathrm{H}=\mathrm{Q}^{2} /\left(2 \mathrm{gA}_{2}{ }^{2}\right)$

Substituting $Q$ in equation 5 , then

$\mathrm{H}_{\mathrm{cr}}=\left[\left(\mathrm{P}_{1}-\mathrm{P}_{2}\right) / \rho g\right]^{2} /\left(2 \mathrm{gA}_{2}^{2}\right)=\left[\mathrm{C}^{2}\left(1 / \mathrm{r}_{2}{ }^{2}-1 / \mathrm{r}_{1}{ }^{2}\right)\right.$ $/ 2 \mathrm{~g}]^{2} /\left(2 \mathrm{gA}_{2}{ }^{2}\right)$
Where $\mathrm{P}_{1}$ is the pressure above the liquid plus liquid pressure, is $\mathrm{A}_{2}$ orifice cross sectional area, and $\mathrm{H}_{\mathrm{cr}}$ is a critical height. The theoretical formula and experimental values shows that there is an effect on critical height when the size and shape of containers are changed. To correlate the theoretical and experimental results, needs to be covered into another paper, but the hint can be borrowed from Reynold's number formula which uses $\mathrm{d}=$ $4 \mathrm{~A} /$ circumference for the diameter of non circular cross sections.

For equation $Y=1.19 x^{2}-14.56 x+38.1$ obtained from data in Table 7 , a quadratic equation of a nature $a x^{2}+b x+c=0$ is solved by a formula $x_{1,2}=\left[-b \pm\left(b^{2}-4 a c\right)^{0.5}\right] / 2 a$. The solution gives $x^{1}=$ $8.45^{\circ}$ and $x^{2}=3.8^{\circ}$ receptively. This shows that there is a critical taper angle at which below that value, no free vortex can be formed in conical containers. Experiments have shown that vortex formation starts at an angle greater than $8.5^{\circ}$.

\section{CONCLUSIONS}

1. The critical height in pouring basins is the function of basin cross sectional area, shape and size.

2. Circular pouring basin produces vortex at higher heights when compared to rectangular shapes. The higher the rectangular side ratios, the smaller is the critical height.

3. The size and shape of the orifice dictates the critical height of the fluid in the pouring basin. It is the lowest when using circular orifices and highest when using square orifices.

4. In conical pouring basin, the higher the inlet/outlet diameter ratio, the higher is the critical height.

5. The orifice offset from the center of the basin, the lower is the critical height.

6. Critical height is a function of pressure and specific gravity of liquid. The lower the pressure, the higher is the critical height value. 
7. A formula has been proposed for calculating theoretical critical height.

8. Vortex formation in conical containers is experienced when the taper angle is greater than $8.5^{\circ}$.

9. The correlation between the theoretical critical height and experimental values will be discussed in another paper.

\section{ACKNOWLEDGEMENTS}

The author wishes to acknowledge the contributions of the following students who carried out most of experiments during their undergraduate studies as student projects. These are Silayo E.P, Mahalila B.B. and Khamisi A. Many thanks should go to Komba $\mathrm{P}$; for drawing graphs and diagrams.

\section{REFERENCES}

[1] DERGARABEDIAN P: "The behavior of vortex motion in an Emptying Container," Heat Trans Proc. and Fluid Mech. Inst., Stanford Univ. Press, Stanford.1960, pp.47-61.

[2] MILES,J. W "Note on the damping of free surface oscillation due to drainage", J. Fluid Mech. 12, 1962, 438-440.

[3] SAAD, M. A and OLVER, D.A "Linearized Time dependent FreeSurface Flow in Rectangular and Cylindrical Tank." Proc. Heat Transfer and Fluid Mech.Inst. Stanford University Press, Stanford, Califonia 1964, pp. 81-99

[4] BHUTA P. G and KOVAL L. R: slashing of a liquid in a draining or filling tank under variable g conditions Symposium on fluid mechanics and heat transfer under low gravitational conditions, Lockheed Res. Lab. Paolo, Atto, Califonia.1965

[5] LUBIN, B.A and SPRINGER, G.S: "The Formation of a dip on the surface of a liquid draining from a tank" J. Fluid Mech. (1967), Vol. 29, part 2 pp. 385-390
[6] TITOV N.D A and STEPANOV U.A: Technologia Litinova Proizvodstva, 3 rd Ed.1985

[7] DAUGHERLY: Fluid Mechanics with Engineering Applications. $8^{\text {th }}$ Editions, McGraw-Hill Book Company. 1985

[8] GULLIVER J.S., RINDLES A.J: "Weak vortices at vertical intakes", Journal of Hydraulic Engineering, Vol. 113. No.9, September, 1987 p. 1101-1116.

[9] CAMPBELL J.: Review of fluidity in castings; IBF Annual Congress, 1991

[10] RUNYORO J. J: Design of Gating System ", Ph.D. thesis, Department of Metallurgy and Materials, University of Birmingham. 1992.

[11] CAMPBELL J.: Castings Butterworth Heinemann 1991, p. 19-20

[12] RUNYORO J.J, BOUTRABI S.M. and CAMPBELL J.: "Critical Gate Velocities For Film- forming casting Alloys: A Basis for Process classification"AFS Transactions. 1991. p 225-234.

[13] LUCAS S. K, BRAKE J. R and KUCCER A.: "A boundary Integral method applied to water coning in oil reservoirs", Journal Australian Mathematical Society Ser. B 32 (1991), p. 261-283.

[14] RUNYORO J.J and CAMPBELLJ.: the running and gating of right alloys, Journal The Foundryman, April. 1992, p.117-124

[15] YONOMOTO $\mathrm{T}$ and TASAKAK: "Liquid and gas entrainment to a small break from a stratified two-phase region", Int. Journal Multiphase Flow Vol. 17, No. 6, 1991, pp. 745-765

[16] SMOGLIE C and REINMAN J.J.: "Twophase flow through small branches in a horizontal pipe with stratified flow", Internal Journal Multiphase Flow 12, 1986. pp. 609-62 
Table 1 Critical height (Hcr) obtained from various size and shapes of pouring basins and orifices. The round orifice is placed at the center of the basin.

\begin{tabular}{|c|c|c|c|c|c|}
\hline \multicolumn{2}{|c|}{ Pouring basin } & \multicolumn{2}{|c|}{ Orifice } & \multirow{2}{*}{$\begin{array}{c}\text { Critical } \\
\text { height }\left(\mathrm{H}_{\mathrm{cr}}\right) \\
\mathrm{mm}\end{array}$} & \multirow[t]{2}{*}{ Characteristic equation } \\
\hline Shape & $\begin{array}{l}\text { Area } \times 10^{3} \\
\left(\mathrm{~mm}^{2}\right)\end{array}$ & Shape & Area $\left(\mathrm{mm}^{2}\right)$ & & \\
\hline \multirow{8}{*}{ Square } & 8.1 & \multirow{8}{*}{ Round } & \multirow{4}{*}{78.5} & 4 & \multirow{4}{*}{$\begin{array}{c}Y=1.3 \times-6.95 \\
R^{2}=0.99\end{array}$} \\
\hline & 10 & & & 6 & \\
\hline & 14.4 & & & 11 & \\
\hline & 19.6 & & & 19 & \\
\hline & 9.6 & & \multirow{4}{*}{95} & 5.5 & \multirow{4}{*}{$\begin{array}{c}Y=1.27 x-6.7 \\
R^{2}=0.99\end{array}$} \\
\hline & 11.5 & & & 8.4 & \\
\hline & 15.3 & & & 11.6 & \\
\hline & 21 & & & 20.3 & \\
\hline \multirow{5}{*}{$\begin{array}{c}\text { Rectangle } \\
1: 2\end{array}$} & 10.5 & \multirow{5}{*}{ Round } & \multirow{5}{*}{78.5} & 8 & \multirow{5}{*}{$\begin{array}{c}Y=1.69 x-9.48 \\
R^{2}=0.98\end{array}$} \\
\hline & 12.6 & & & 13 & \\
\hline & 14.7 & & & 15 & \\
\hline & 16.8 & & & 18 & \\
\hline & 20 & & & 25 & \\
\hline \multirow{4}{*}{$\begin{array}{c}\text { Rectangle } \\
1: 3\end{array}$} & 13.8 & \multirow{4}{*}{ Round } & \multirow{4}{*}{95} & 14.7 & \multirow{4}{*}{$\begin{array}{c}Y=1.58 x-8.15 \\
R^{2}=0.96\end{array}$} \\
\hline & 15.9 & & & 16 & \\
\hline & 18 & & & 19.3 & \\
\hline & 22 & & & 27.2 & \\
\hline \multirow{8}{*}{ Circle } & 3.8 & \multirow{4}{*}{ Round } & \multirow{4}{*}{78.5} & 4 & \multirow{4}{*}{$\begin{array}{c}Y=1.82 x-2.36 \\
R^{2}=0.99\end{array}$} \\
\hline & 6.4 & & & 9 & \\
\hline & 11.3 & & & 20 & \\
\hline & 17.7 & & & 29 & \\
\hline & 4.1 & \multirow{4}{*}{ Round } & \multirow{4}{*}{95} & 5.4 & \multirow{4}{*}{$\begin{array}{c}Y=1.61 x+0.09 \\
R^{2}=0.95\end{array}$} \\
\hline & 7.1 & & & 11 & \\
\hline & 12.4 & & & 23.5 & \\
\hline & 19.8 & & & 30.1 & \\
\hline
\end{tabular}


Table 2 The critical heights (Hcr) obtained from various size and shapes of pouring basins and orifices. The round orifices of various sizes are placed in the center of the basin.

\begin{tabular}{|c|c|c|c|c|c|}
\hline \multicolumn{2}{|c|}{ Pouring basin } & \multicolumn{2}{|c|}{ Orifice } & \multirow{2}{*}{$\begin{array}{c}\text { Critical } \\
\text { height } \\
\left(\mathbf{H}_{\mathrm{cr}}\right) \mathrm{mm}\end{array}$} & \multirow{2}{*}{$\begin{array}{c}\text { Characteristic } \\
\text { equation }\end{array}$} \\
\hline Shape & $\begin{array}{c}\text { Area x103 } \\
\left(\mathrm{mm}^{2}\right)\end{array}$ & Shape & $\begin{array}{l}\text { Area } \\
\left(\mathrm{mm}^{2}\right)\end{array}$ & & \\
\hline \multirow{8}{*}{ Square } & \multirow{4}{*}{40} & \multirow{8}{*}{ Round } & 63.6 & 8.4 & \multirow{4}{*}{$\begin{array}{c}Y=0.047 x+4.73 \\
R^{2}=0.87\end{array}$} \\
\hline & & & 132.7 & 9.8 & \\
\hline & & & 176.7 & 12.3 & \\
\hline & & & 201.1 & 15.3 & \\
\hline & \multirow{4}{*}{10} & & 78.5 & 10 & \multirow{4}{*}{$\begin{array}{c}\mathrm{Y}=0.05 \mathrm{x}+6.60 \\
\mathrm{R}^{2}=0.98\end{array}$} \\
\hline & & & 176.7 & 15 & \\
\hline & & & 314.2 & 24 & \\
\hline & & & 490.9 & 30 & \\
\hline \multirow{4}{*}{$\begin{array}{c}\text { Rectangle } \\
1: 2\end{array}$} & \multirow{4}{*}{10} & \multirow{4}{*}{ Round } & 78.5 & 9 & \multirow{4}{*}{$\begin{array}{c}Y=0.03 x+6.89 \\
R^{2}=0.92\end{array}$} \\
\hline & & & 176.7 & 12 & \\
\hline & & & 314.2 & 20 & \\
\hline & & & 490.9 & 22 & \\
\hline \multirow{4}{*}{$\begin{array}{c}\text { Rectangle } \\
1: 3\end{array}$} & \multirow{4}{*}{40} & \multirow{4}{*}{ Round } & 63.6 & 6.1 & \multirow{4}{*}{$\begin{array}{c}Y=0.05 x+3.00 \\
R^{2}=0.97\end{array}$} \\
\hline & & & 132.7 & 10 & \\
\hline & & & 176.7 & 11.1 & \\
\hline & & & 201.1 & 13.4 & \\
\hline \multirow{4}{*}{$\begin{array}{c}\text { Rectangle } \\
1: 4\end{array}$} & \multirow{4}{*}{10} & \multirow{4}{*}{ Round } & 78.5 & 7 & \multirow{4}{*}{$\begin{array}{c}\mathrm{Y}=0.02 \mathrm{x}+6.16 \\
\mathrm{R}^{2}=0.93\end{array}$} \\
\hline & & & 176.7 & 11 & \\
\hline & & & 314.2 & 15 & \\
\hline & & & 490.9 & 17 & \\
\hline \multirow{4}{*}{$\begin{array}{c}\text { Rectangle } \\
1: 4\end{array}$} & \multirow{4}{*}{40} & \multirow{4}{*}{ Round } & 63.6 & 8.6 & \multirow{4}{*}{$\begin{array}{c}Y=0.07 x+3.02 \\
R^{2}=0.92\end{array}$} \\
\hline & & & 132.7 & 11.3 & \\
\hline & & & 176.7 & 15.4 & \\
\hline & & & 201.1 & 19.2 & \\
\hline \multirow{8}{*}{ Circle } & \multirow{4}{*}{11.3} & \multirow{4}{*}{ Round } & 78.5 & 25 & \\
\hline & & & 176.7 & 33 & $Y=0.06 x+21.33$ \\
\hline & & & 314.2 & 40 & $\mathrm{R}^{2}=0.99$ \\
\hline & & & 490.9 & 50 & \\
\hline & & & 63.6 & 13.7 & \\
\hline & 40 & Round & 132.7 & 23.6 & $Y=0.18 x+1.27$ \\
\hline & & & 176.7 & 34.4 & $\mathrm{R}^{2}=0.99$ \\
\hline & & & 201.1 & 38.3 & \\
\hline
\end{tabular}


Table 3 Comparing the effect of offsetting the orifice in the pouring basin on the critical height for different shapes of basins with the same area.

\begin{tabular}{|c|c|c|c|c|c|}
\hline \multicolumn{2}{|c|}{ Pouring Basin } & \multicolumn{2}{|c|}{ orifice } & \multicolumn{2}{|c|}{ Critical Heights } \\
\hline Shape & $\begin{array}{c}\text { Area } \times 10^{3} \\
\left(\mathrm{~mm}^{2}\right)\end{array}$ & Shape & $\begin{array}{c}\text { Area } \\
\left(\mathrm{mm}^{2}\right)\end{array}$ & $\begin{array}{l}\text { Orifice in the } \\
\text { center of basin }\end{array}$ & $\begin{array}{l}\text { Orifice offset } \\
\text { from the center }\end{array}$ \\
\hline \multirow{5}{*}{ Square } & \multirow{5}{*}{5.2} & \multirow{5}{*}{ Round } & & & $70 \mathrm{~mm}$ offset \\
\hline & & & 132.7 & 26.7 & 18.4 \\
\hline & & & 176.7 & 38.9 & 20.3 \\
\hline & & & 201.1 & 43.8 & 24.9 \\
\hline & & & 314.2 & 47.4 & 30.8 \\
\hline \multirow{5}{*}{$\begin{array}{c}\text { Rectangle } \\
1: 3\end{array}$} & \multirow{5}{*}{5.2} & \multirow{5}{*}{ Round } & & & $40 \mathrm{~mm}$ offset \\
\hline & & & 132.7 & 17.6 & 19.6 \\
\hline & & & 176.7 & 19.3 & 28.1 \\
\hline & & & 201.1 & 20.8 & 31.5 \\
\hline & & & 314.2 & 25.5 & 33.7 \\
\hline \multirow{5}{*}{ Circle } & \multirow{5}{*}{5.2} & \multirow{5}{*}{ Round } & & & $25 \mathrm{~mm}$ offset \\
\hline & & & 132.7 & 32.3 & 40.1 \\
\hline & & & 176.7 & 39.1 & 44 \\
\hline & & & 201.1 & 45.3 & 47.8 \\
\hline & & & 314.2 & 48.2 & 50.3 \\
\hline
\end{tabular}

Table 4 Comparing the effect of offsetting the orifices of different diameters in the trapezoidal shaped pouring basin. The cross sectional sizes are $200 \times 80 \times 30 \mathrm{~mm}$

\begin{tabular}{|c|c|c|c|c|c|}
\hline \multirow{2}{*}{$\begin{array}{c}\text { Orifice } \\
\text { area } \\
(\mathrm{mm})\end{array}$} & \multirow{2}{*}{$\begin{array}{l}\text { Offset } \\
\text { from } \\
\text { centre } \\
(\mathrm{mm})\end{array}$} & \multicolumn{4}{|c|}{ Critical height (mm) } \\
\hline & & $\begin{array}{c}\text { Left } \\
\text { (short } \\
\text { side) } \\
\end{array}$ & $\begin{array}{c}\text { Characteristic } \\
\text { equation }\end{array}$ & $\begin{array}{l}\text { Right } \\
\text { (long } \\
\text { side) } \\
\end{array}$ & $\begin{array}{c}\text { Characteristic } \\
\text { equation }\end{array}$ \\
\hline 78.5 & \multirow{4}{*}{40} & 11 & \multirow[t]{4}{*}{$\mathrm{Y}=4.07 \mathrm{Ln}(\mathrm{x})-7.14$} & 13 & \multirow[t]{4}{*}{$Y=4.61 \operatorname{Ln}(x)-7.27$} \\
\hline 176.7 & & 13 & & 16 & \\
\hline 314.2 & & 17 & & 19 & \\
\hline 490.9 & & 18 & & 21 & \\
\hline 78.5 & \multirow{4}{*}{80} & 6 & \multirow{4}{*}{$\begin{array}{c}\mathrm{Y}=4.51 \operatorname{Ln}(\mathrm{x})- \\
13.46\end{array}$} & 8 & \multirow{4}{*}{$\begin{array}{c}\mathrm{Y}=4.40 \operatorname{Ln}(\mathrm{x})- \\
10.65\end{array}$} \\
\hline 176.7 & & 10 & & 13 & \\
\hline 314.2 & & 13 & & 15 & \\
\hline 490.9 & & 14 & & 16 & \\
\hline
\end{tabular}


Table 5 Comparing the effect of offsetting the orifice in the pouring basin on the critical height for different sizes and shapes of basins and orifices.

\begin{tabular}{|c|c|c|c|c|c|c|}
\hline \multicolumn{2}{|c|}{ Pouring Basin } & \multicolumn{2}{|c|}{ Orifice } & \multirow{2}{*}{$\begin{array}{l}\text { Orifice } \\
\text { offset from } \\
\text { center } \\
(\mathrm{mm})\end{array}$} & \multicolumn{2}{|c|}{ Critical Height (mm) } \\
\hline Shape & $\begin{array}{c}\text { Area } \\
\text { x103 } \\
\left(\mathrm{mm}^{2}\right)\end{array}$ & Shape & Area $\left(\mathrm{mm}^{2}\right)$ & & Measured & Characteristic equation \\
\hline \multirow{12}{*}{$\begin{array}{l}\text { Rect } \\
1: 2\end{array}$} & \multirow{12}{*}{20} & \multirow{12}{*}{ Round } & 78.5 & \multirow{3}{*}{20} & 26 & \multirow{3}{*}{$\begin{array}{c}Y=0.09 x+19.1 \\
R^{2}=1\end{array}$} \\
\hline & & & 176.7 & & 35 & \\
\hline & & & 314.2 & & 47 & \\
\hline & & & 78.5 & \multirow{3}{*}{40} & 22 & \multirow{3}{*}{$\begin{array}{c}Y=0.09 x+15.5 \\
R^{2}=1\end{array}$} \\
\hline & & & 176.7 & & 32 & \\
\hline & & & 314.2 & & 43 & \\
\hline & & & 78.5 & \multirow{3}{*}{60} & 20 & \multirow{3}{*}{$\begin{array}{c}Y=0.06 x+15.0 \\
R^{2}=1\end{array}$} \\
\hline & & & 176.7 & & 25 & \\
\hline & & & 314.2 & & 34 & \\
\hline & & & 78.5 & \multirow{3}{*}{80} & 6 & \multirow{3}{*}{$\begin{array}{c}Y=0.06 x+2.67 \\
R^{2}=0.93\end{array}$} \\
\hline & & & 176.7 & & 15 & \\
\hline & & & 314.2 & & 20 & \\
\hline \multirow{9}{*}{ Circle } & \multirow{9}{*}{11.3} & \multirow{9}{*}{ Round } & 78.5 & \multirow{3}{*}{20} & 38 & \multirow{3}{*}{$\begin{array}{c}\mathrm{Y}=0.05 \mathrm{x}+34.5 \\
\mathrm{R}^{2}=1\end{array}$} \\
\hline & & & 176.7 & & 43 & \\
\hline & & & 314.2 & & 49 & \\
\hline & & & 78.5 & \multirow{3}{*}{30} & 30 & \multirow{3}{*}{$\begin{array}{c}Y=0.07 x+25.7 \\
R^{2}=0.97\end{array}$} \\
\hline & & & 176.7 & & 39 & \\
\hline & & & 314.2 & & 46 & \\
\hline & & & 78.5 & \multirow{3}{*}{40} & 20 & \multirow{3}{*}{$\begin{array}{c}Y=0.06 x+15.9 \\
R^{2}=1\end{array}$} \\
\hline & & & 176.7 & & 26 & \\
\hline & & & 314.2 & & 33 & \\
\hline
\end{tabular}

Table 6 Comparing the effect of pressure on critical heights of water, petrol, and kerosene using a $6 \mathrm{~mm}$ diameter orifice in cylinder with internal diameter of $70 \mathrm{~mm}$ and a rectangular box of $200 \times 100 \mathrm{~mm}$ in cross section. Specific gravities of water 1, Petrol 0.7-0.75, Kerosene, $0.75-0.8$

\begin{tabular}{|c|c|c|c|c|c|c|}
\hline \multirow{2}{*}{$\begin{array}{c}\text { Pressure } \\
\text { (bars) }\end{array}$} & \multicolumn{3}{|c|}{ Cylindrical container } & \multicolumn{3}{c|}{ Rectangular container } \\
\cline { 2 - 7 } & Water & Petrol & Kerosene & Water & Petrol & Kerosene \\
\hline 1.5 & 10.3 & 3.7 & 4.0 & 5.7 & 2.3 & 2.7 \\
\hline 1.0 & 12.7 & 4.7 & 5.7 & 6.7 & 3.3 & 3.7 \\
\hline 0.5 & 14.0 & 5.7 & 7.0 & 8.9 & 5.0 & 5.7 \\
\hline Characteristic & $\mathrm{Y}=-3.7 \mathrm{x}$ & $\mathrm{Y}=-2 \mathrm{x}$ & $\mathrm{Y}=-3 \mathrm{x}+8.57$ & $\mathrm{Y}=-3.2 \mathrm{x}$ & $\mathrm{Y}=-2.7 \mathrm{x}$ & $\mathrm{Y}=-3 \mathrm{x}+7.03$ \\
equation & +16.03 & +6.7 & $\mathrm{R}^{2}=1$ & +10.3 & +6.23 & $\mathrm{R}^{2}=0.96$ \\
& $\mathrm{R}^{2}=0.97$ & $\mathrm{R}^{2}=1$ & & $\mathrm{R}^{2}=0.96$ & $\mathrm{R}^{2}=0.98$ & \\
\hline
\end{tabular}


Effect of inlet and outlet sizes of conical basins in formation of critical heights when using water.

General characteristic equation $Y=1.19 x^{2}-14.56 x+38.1$

$\mathrm{R}^{2}=0.90, \mathrm{Y}=$ critical height $(\mathrm{mm}), \mathrm{x}=$ taper angle in degrees.

\begin{tabular}{|c|c|c|c|}
\hline $\begin{array}{l}\text { Inlet diameter } \\
(\mathrm{mm})\end{array}$ & $\begin{array}{c}\text { Outlet diameter } \\
(\mathrm{mm})\end{array}$ & $\begin{array}{c}\text { Taper angle } \\
\text { (degrees) }\end{array}$ & $\begin{array}{c}\text { Critical height } \\
(\mathrm{mm})\end{array}$ \\
\hline 40 & \multirow{4}{*}{10} & 4.8 & - \\
\hline 60 & & 7.9 & - \\
\hline 80 & & 11.0 & 20.0 \\
\hline 100 & & 14.0 & 70.0 \\
\hline 45 & \multirow{4}{*}{15} & 5.3 & 0 \\
\hline 50 & & 8.1 & 0 \\
\hline 75 & & 10.8 & 23.4 \\
\hline 100 & & 14.3 & 72.6 \\
\hline 45 & \multirow{8}{*}{20} & 2.9 & - \\
\hline 40 & & 3.2 & - \\
\hline 50 & & 6.5 & - \\
\hline 60 & & 7.9 & - \\
\hline 80 & & 9.5 & 8.0 \\
\hline 75 & & 10.4 & 9.1 \\
\hline 100 & & 12.5 & 60.0 \\
\hline 100 & & 13.4 & 66.3 \\
\hline 75 & \multirow{4}{*}{25} & 8.7 & - \\
\hline 80 & & 9.4 & 4 \\
\hline 100 & & 11.8 & 15 \\
\hline 100 & & 12.0 & 15.8 \\
\hline
\end{tabular}

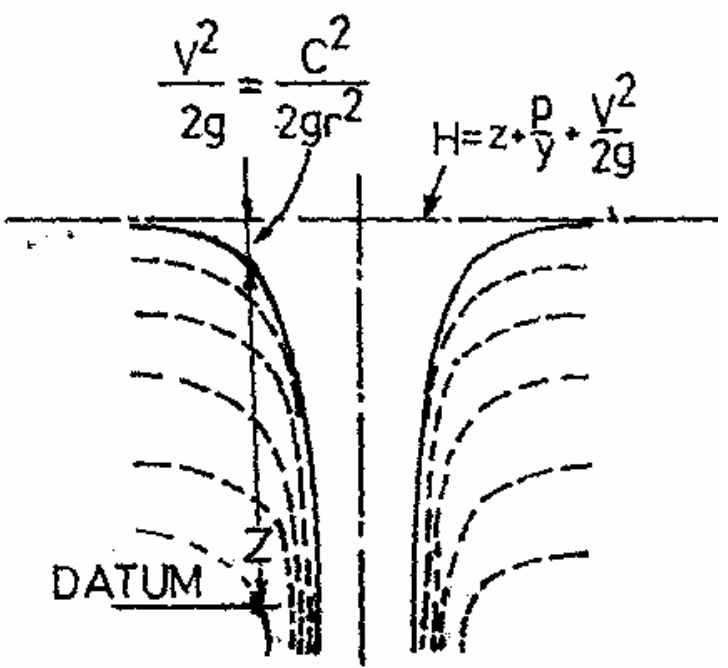

Fig. 1 The energy formula (Bernoulli's theorem) as applied to vortex formation in the liquid draining out of the orifice. 

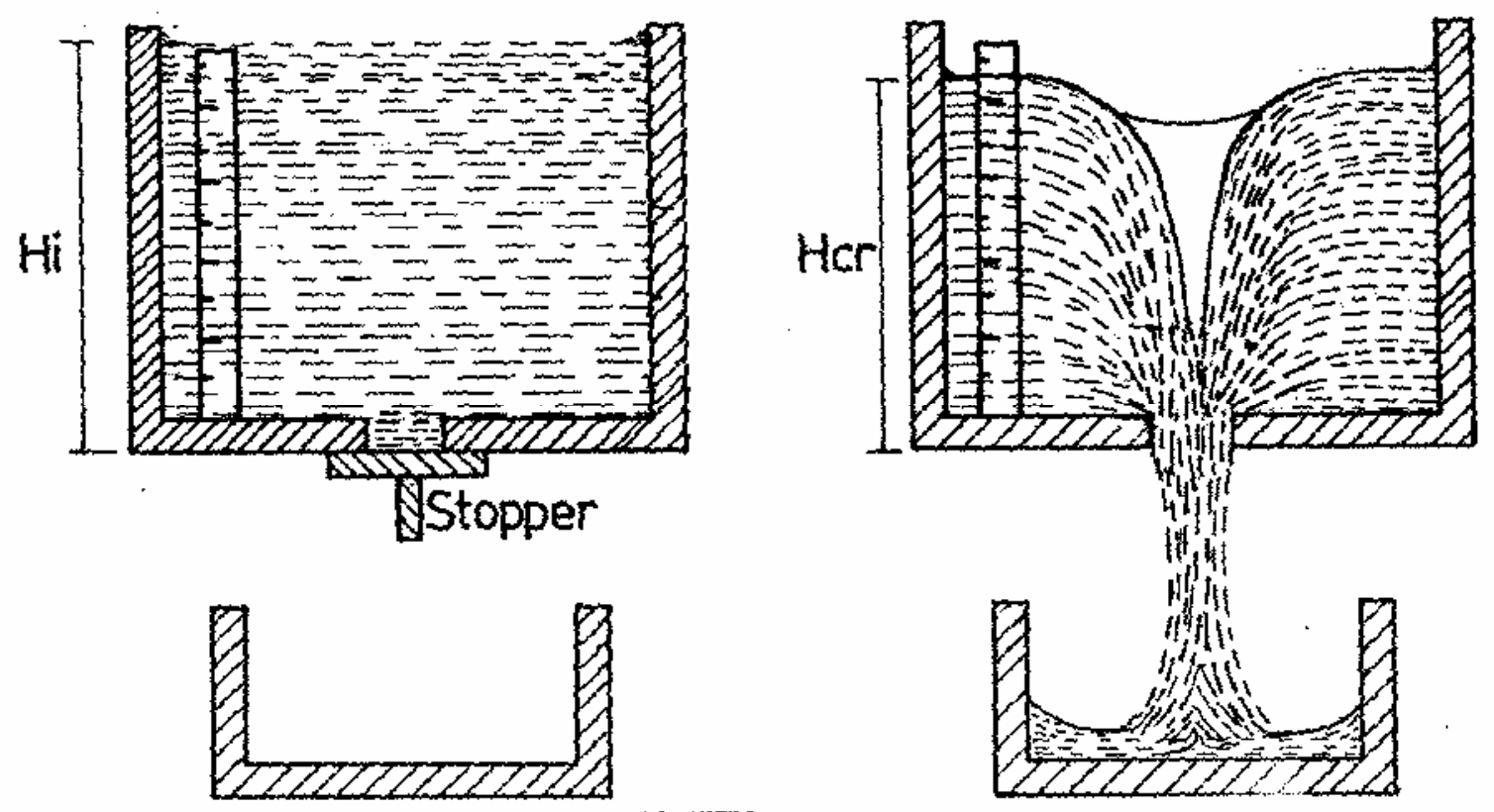

Fig. 2 Typical experimental set up for various pouring basin shapes.
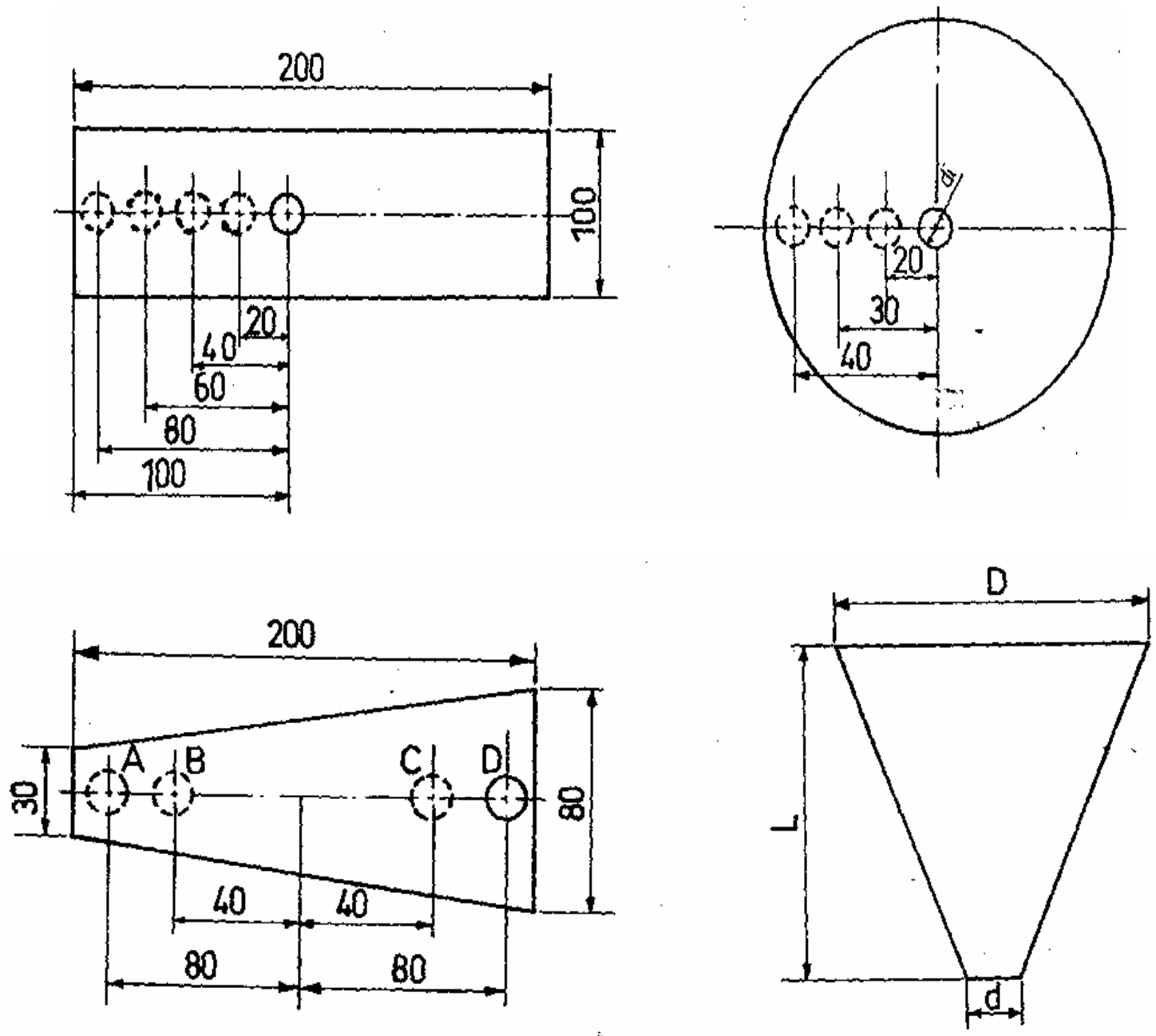


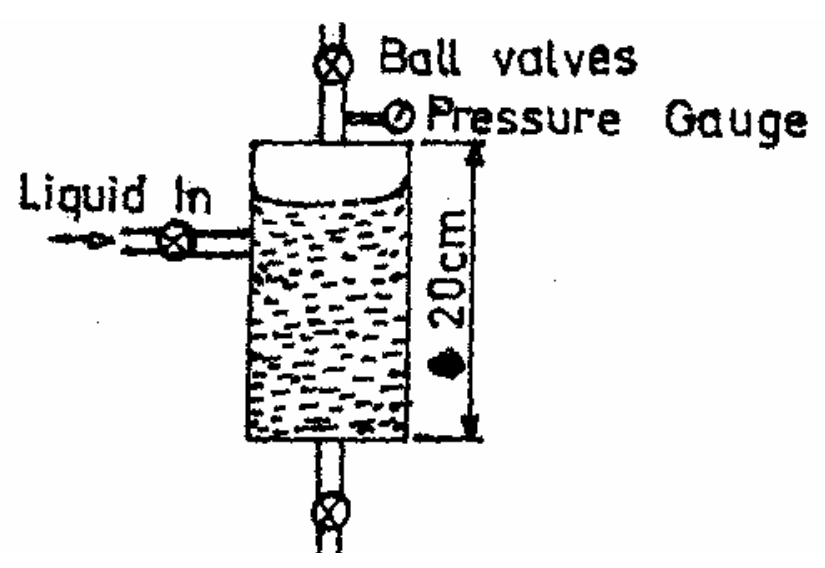

Fig 3: Various shapes of pouring basins used in the experiment.

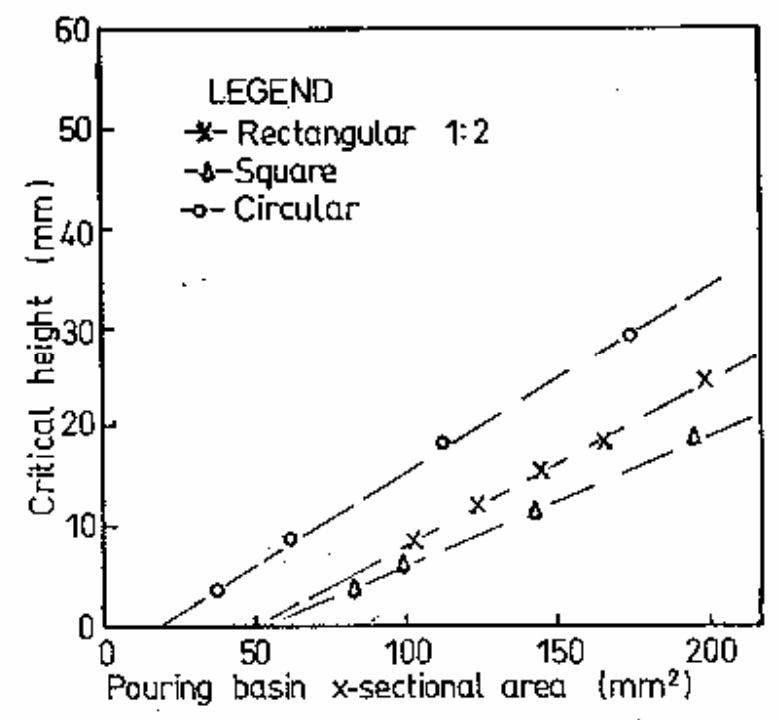

Fig. 4: Critical height versus pouring basin cross sectional area. The orifice opening was $78.5 \mathrm{~mm}^{2}$ placed at the center of the container.

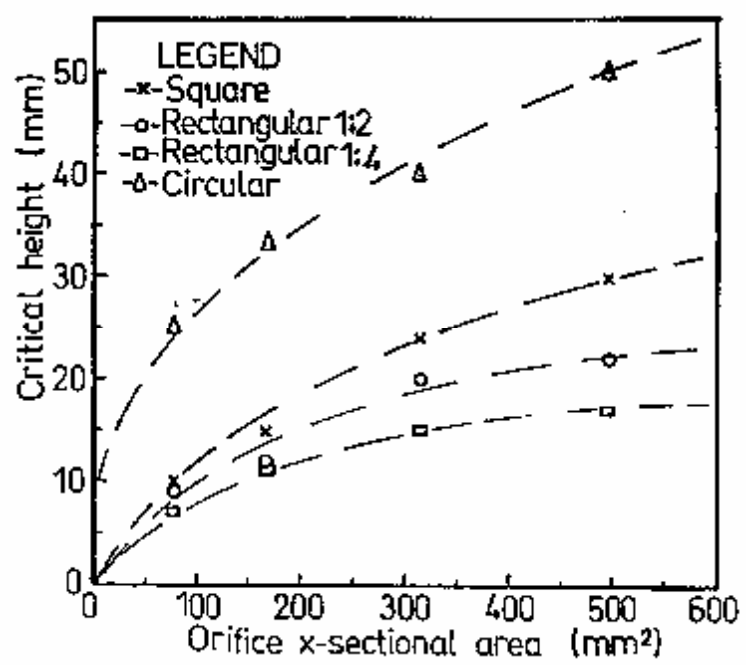

Fig. 5: Critical height versus cross-sectional area of circular orifice placed in the center of $100 \mathrm{~cm}^{2}$ pouring basins of various shapes.

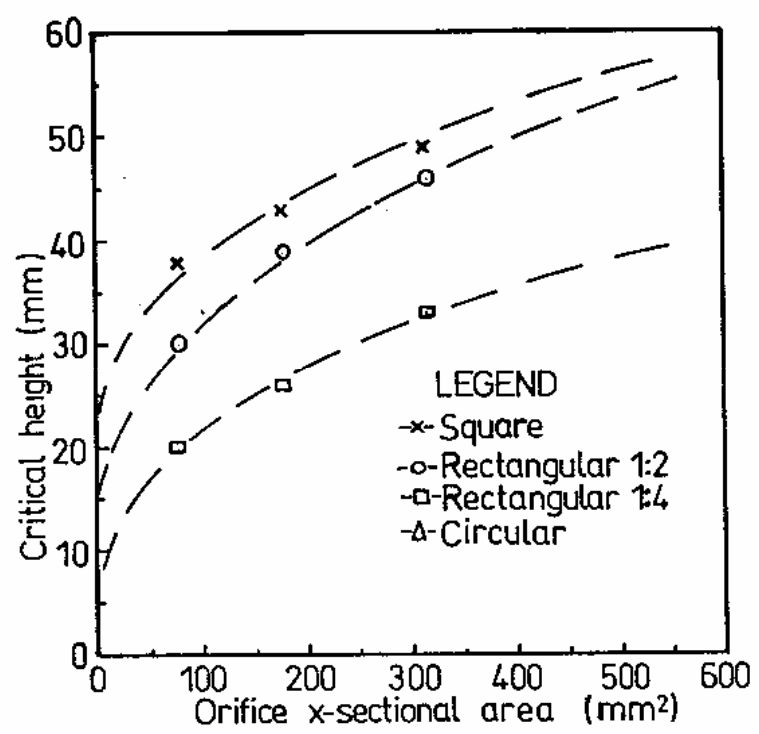

Fig. 6a: Critical height versus cross-sectional area of various shapes of orifice placed in the center of $110 \mathrm{~cm}^{2}$ cylindrical pouring basin.

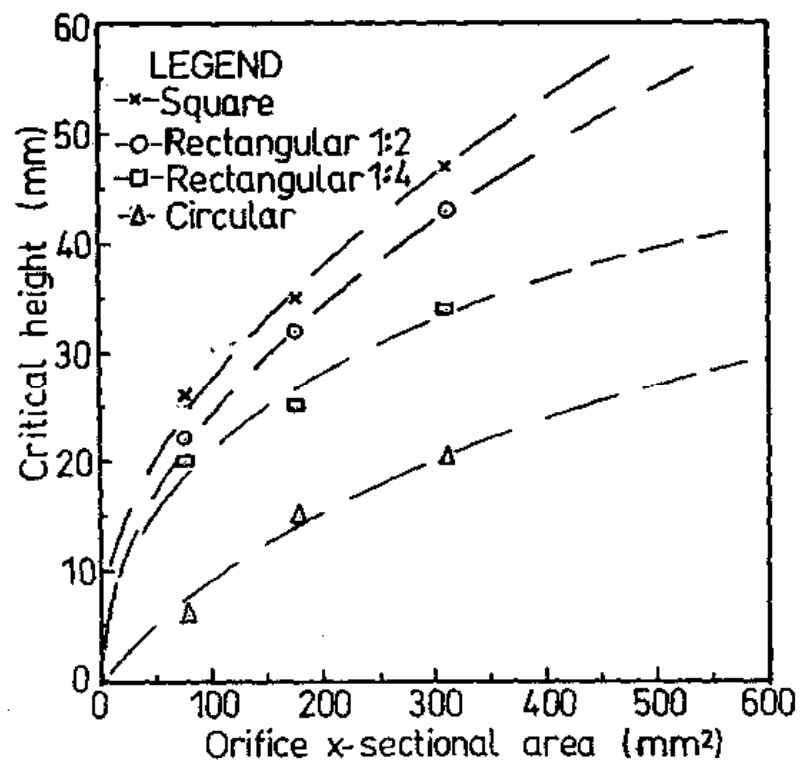

Fig. 6b: Critical height versus cross-sectional area of orifice of various sizes and shapes placed in the center of $200 \mathrm{~cm}^{2}$ rectangular (1:2) basin. 


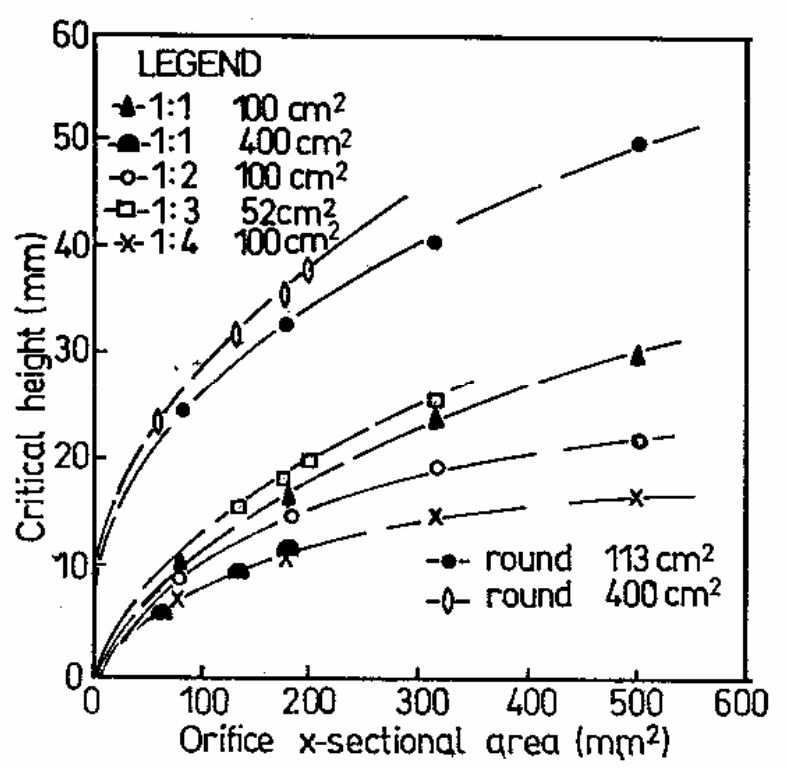

Fig. 7: Effect of pouring basin size and shape on critical height for circular orifices centrally located.

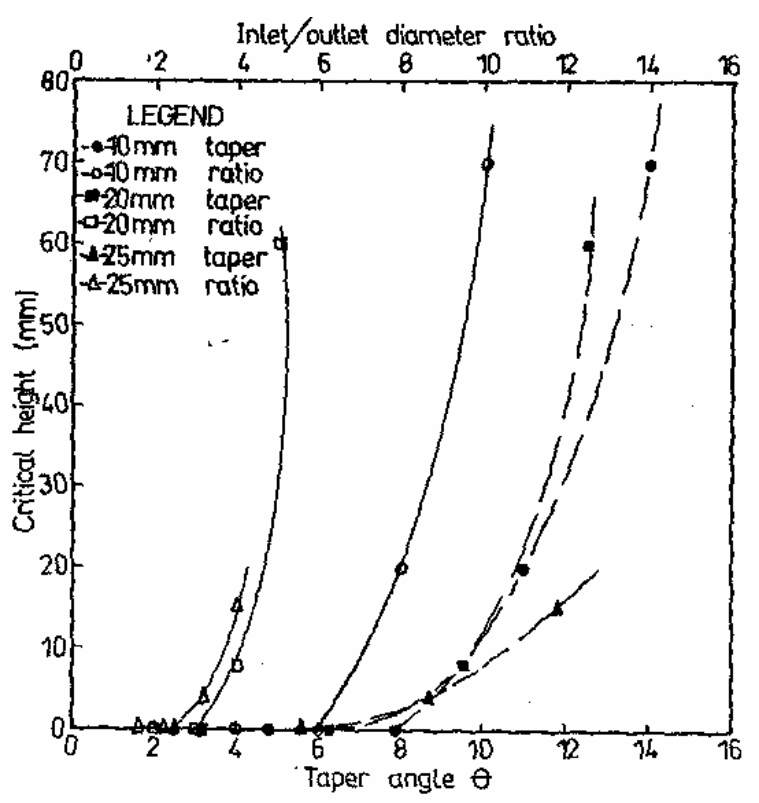

Fig. 8: The critical height versus inlet / outlet ratio of the conical pouring basin.

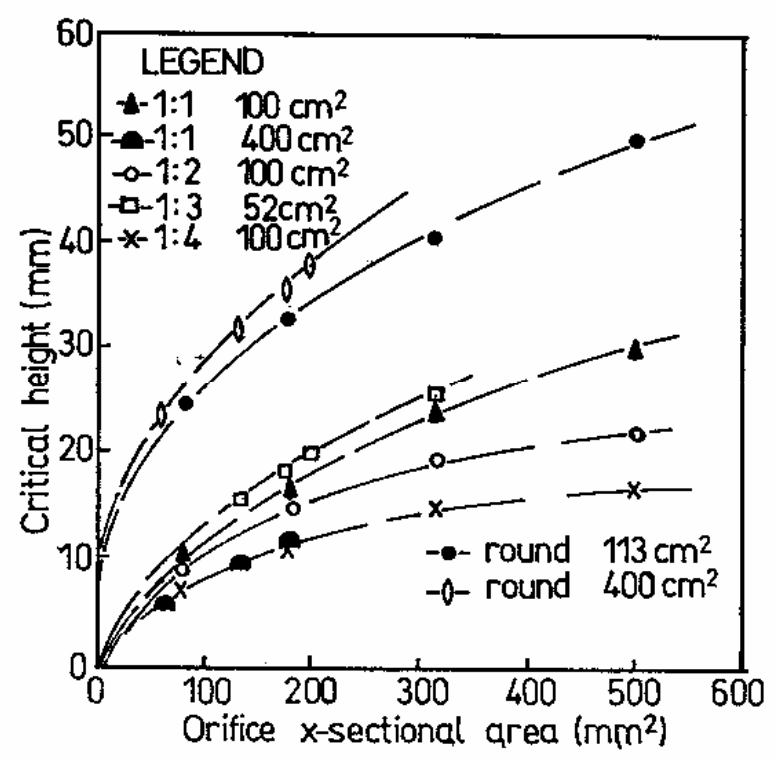

Fig. 9a: Critical height versus orifice offset from the center using a $200 \times 100 \mathrm{~mm}$ pouring basin.

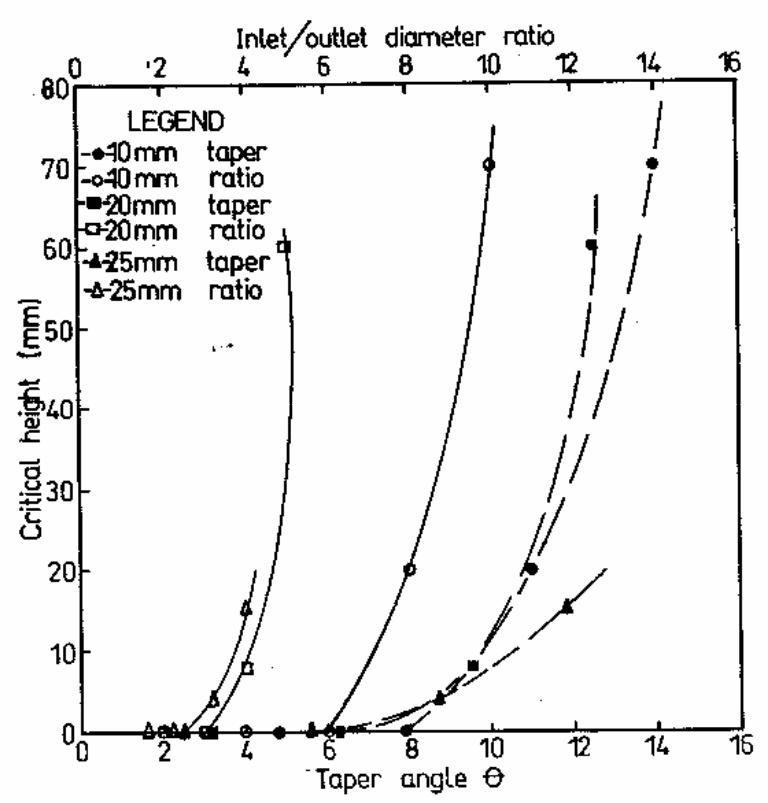

Fig. 9b: Critical height versus orifice offset from the center using a trapezoidal pouring basin. Orifice openings are 10, 15, 20 and 25 $\mathrm{mm}$ diameters. 


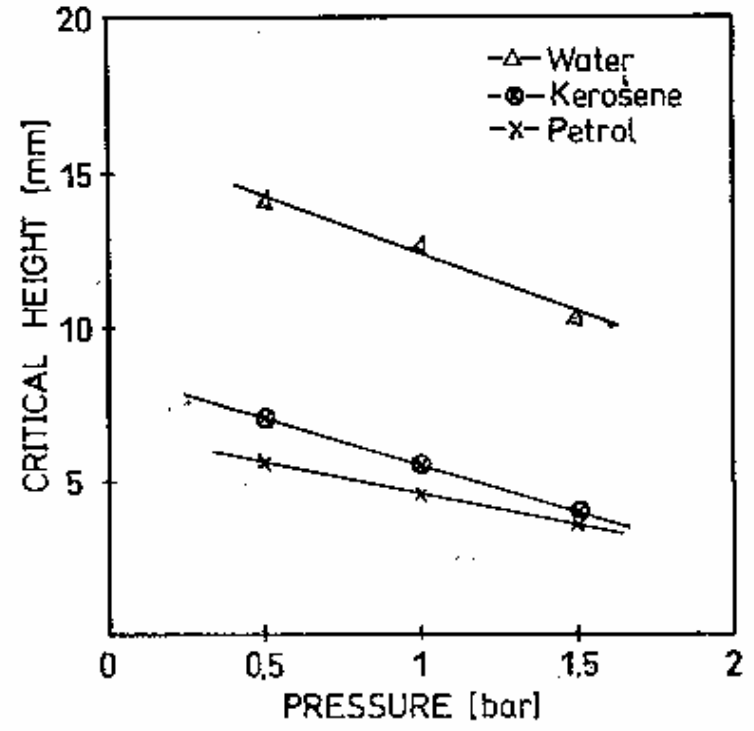

Fig. 10a. Variation of the critical height with pressure in a $38.5-\mathrm{cm}^{2}$ circular pipe with centrally located orifice of $6 \mathrm{~mm}$ diameter.

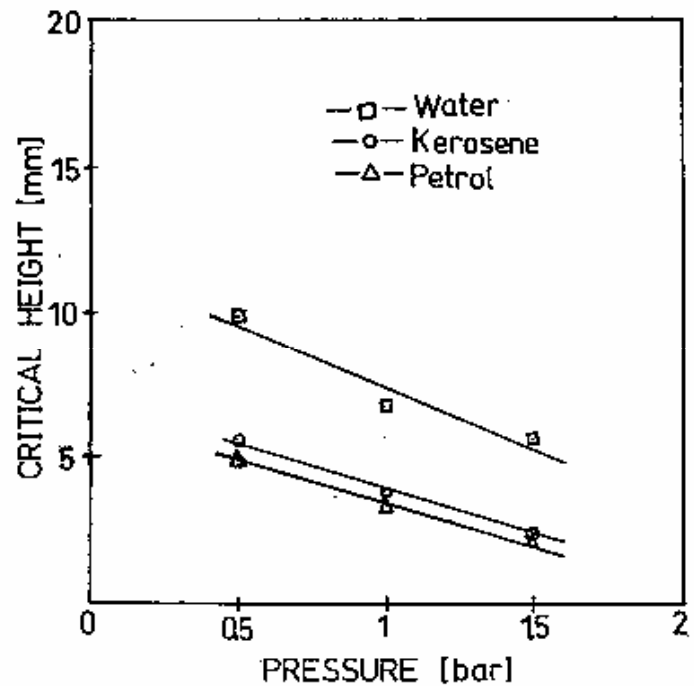

Fig. 10b: Variation of the critical height with pressure in a $200-\mathrm{cm}^{2}$ rectangular section (1:2) with centrally located orifice of $6 \mathrm{~mm}$ diameter 